\title{
ANALISIS EVOLUSI HIDROGEOKIMIA AIRTANAH DI PULAU KORAL PRAMUKA, KEPULAUAN SERIBU
}

\author{
Ahmad Cahyadi, Tjahyo Nugroho Adji dan Muh Aris Marfai \\ Jurusan Geografi Lingkungan, Fakultas Geografi, Universitas Gadjah Mada Yogyakarta
}

Email: ahmadcahyadi@geo.ugm.ac.id

\begin{abstract}
ABSTRAK
Pulau Koral Pramuka merupakan salah satu pulau koral sangat kecil yang terdapat di Gugusan Kepualauan Seribu. Kedudukannya sebagai ibukota kabupaten menyebabkan jumlah penduduk semakin meningkat. Kondisi ini kemungkinan menyebabkan terjadinya penurapa airtanah yang semakin banyak dan kemungkinan pencemaran airtanah yang semakin tinggi. Selain itu, keberadaan Pulau Koral Pramuka sebagai pulau kecil menyebabkan secara alami memiliki karakteristik curah hujan yang sedikit serta kerawanan terhadap intrusi air laut yang tinggi. Penelitian ini bertujuan untuk melakukan analisis evolusi hidrogrokimia airtanah di Pulau Koral Pramuka.

Pengambilan sampel dilakukan dengan sampel sistematis dengan membuat grid ukuran $100 \mathrm{~m} \times 150 \mathrm{~m}$. Sampel diambil secara acak minimal satu sampel airtanah untuk satu grid. Data yang digunakan berupa kandungan ion mayor di dalam airtanah yang diperoleh berdasarkan analisis laboratorium. Analisis evolusi airtanah dilakukan dengan menggunakan diagram trilinear atau diagram piper.

Hasil analisis menunjukkan bahwa tipe fasies hidrogeokimia airtanah di Pulau Koral Pramuka telah mengalami evolusi dari tipe fasies hidrogeokimia $\mathrm{CaCO}_{3}$ menjadi $\mathrm{MgCl}_{2}$. Tipe fasies hidrogeokimia $\mathrm{CaCO}_{3}$ merupakan tipe fasies hidrogeokimia yang dipengaruhi oleh batuan penyusun Pulau Koral Pramuka yang berupa rombakan bioklastik. Perubahan tipe fasies hidrogeokimia menjadi $\mathrm{MgCl}_{2}$ menunjukkan adanya dampak dari intrusi air laut.
\end{abstract}

Kata kunci: Airtanah, Evolusi, Hidrogeokimia, Pulau Koral Pramuka

\section{PENDAHULUAN}

\section{Latar Belakang}

Pulau Koral (Cay) Pramuka merupakan satu dari 110 pulau yang terletak di gugusan Kepulauan Seribu. Pulau Koral Pramuka terletak di bagian tengah gugusan Kepulauan Seribu pada arah Utara-Selatan, dan terletak di tepi bagian Timur pada gugusan Kepulauan Seribu pada arah Barat-Timur.

Pulau Koral Pramuka secara genesis terbentuk oleh endapan bioklastik yang berasal dari rombakan terumbu karang (Ongkosongo, 2011). Pulau ini tergolong pada pulau datar pada klasifikasi pulau yang dibuat oleh Hehanusa (1993) yang didasarkan pada genesis. Secara geomorfologis, pulau ini merupakan terumbu karang lepas (patch reef).

Luas Pulau Koral Pramuka yang sempit (16,54 hektar), curah hujan yang sedikit dan keberadaannya yang dikelilingi oleh air laut menyebabkan sumberdaya air yang tedapat di Pulau Koral Pramuka menjadi sangat terbatas (Cahyadi, 2012; 2013). Meskipun demikian, sejak ditetapkan sebagai ibukota Kabupaten sejak Tahun 2003, Pulau Koral Pramuka terus mengalami perkembangan, baik dalam hal jumlah penduduk yang terus bertambah, jumlah wisatawan, serta perubahan penggunaan lahan menjadi lahan terbangun yang berupa fasilitas umum, fasilitas wisata dan kantor pemerintahan. Kondisi ini menyebabkan kebutuhan 
sumberdaya air semakin bertambah dan di sisi yang lain terus berkurang akibat hilangnya resapan air.

Kondisi yang tekah dikemukakan di atas menunjukkan adanya ancaman terhadap kelestarian sumberdaya air, khususnya airtanah di Pulau Koral Pramuka di masa mendatang. Salah satu ancaman yang mungkin muncul adalah adanya intrusi air laut. Oleh karena itu perlu adanya suatu kajian terkait dengan hal tersebut, untuk mengetahui dampak dari pembangunan yang telah terjadi terhadap kondisi airtanah saat ini di Pulau Koral Pramuka. Hasil penelitian tersebut akan dapat menjadi sumbangan dan masukan bagi perencanaan pembangunan dimasa mendatang.

Dampak intrusi air laut terhadap airtanah diantaranya dapat dilihat dari kondisi hidrogeokimia airtanah. Hem (1970) dan Gilli et al. (2012) menjelaskan bahwa analisis karakteristik hidrogeokimia dapat digunakan untuk menganalisis proses lingkungan yang terjadi terhadap airtanah, menganalisis tipe batuan yang dominan berpengaruh terhadap kualitas air, kondisi wilayah imbuhan airtanah, lama tinggal airtanah dalam akuifer, sumber mineralisasi yang terjadi serta kontaminan alami dan artifisial yang masuk ke dalam sistem akuifer. Hal ini karena airtanah dalam waktu yang cukup lama dapat melarutkan unsur kimia yang terdapat dalam akuifer tempatnya tersimpan, sehingga mengubah komposisi kimianya (Todd, 1980; Fetter, 1988). Berdasarkan hal tersebut, maka perubahan sifat kimia yang ditunjukkan oleh tipe kimia dan proses hidrogeokimia airtanah akan mencerminkan proses yang pernah terjadi serta dapat digunakan untuk mengetahui jenis batuan yang dominan menyusun suatu akuifer (Stuyfzand, 1991; Hiscock, 2005).

Santosa (2010) menyebutkan bahwa evolusi kimia airtanah dipengaruhi oleh lima faktor utama, yaitu:

1. Genesis atau proses utama yang mempengaruhi pembentukan akuifer di mana airtanah tersimpan;

2. Lingkungan pengendapan dan pembentukkan akuifer penyimpan airtanah terbentuk;

3. Komposisi mineral batuan yang menyusun akuifer penyimpan airtanah;

4. Proses yang terjadi pada airtanah di dalam akuifer; dan dan

5. Lama tinggal airtanah dalam akuifer.

Analisis hidrogeokimia dalam airtanah dapat dengan mudah dilakukan dengan menggunakan suatu diagram atau grafik (Hem, 1970; Todd, 1980 dan Hiscock, 2005). Beberapa tabel dan grafik yang sering digunakan diantaranya adalah diagram batang, diagram lingkaran (pie diagram), diagram stiff, diagram trilinear dan diagram durov. Penggunaan diagram ini dipilih berdasarkan pada tujuan penelitian. Misalnya diagram lingkaran digunakan untuk mengetahui ion yang paling dominan serta keseimbangan anion dan kation, diagram stiff untuk mengetahui tipe kimia airtanah serta diagram trilinear atau yang lebih dikenal dengan diagram piper digunakan untuk mengetahui evolusi kimia yang terjadi pada airtanah.

Analisis hidrogeokimia yang sering dilakukan adalah analisis ion mayor di dalam air (Hem, 1970). Ion mayor di dalam air adalah ion yang menyusun lebih dari $90 \%$ total padatan terlarut yang terdapat dalam air (Hiscock, 2005). Hiscock (2005) menjelaskan lebih lanjut bahwa ion mayor yang terdapat dalam air terdiri dari enam, yaitu kalsium $\left(\mathrm{Ca}^{2+}\right)$, magnesium $\left(\mathrm{Mg}^{2+}\right)$, sodium/natrium $\left(\mathrm{Na}^{+}\right)$, klorida $\left(\mathrm{Cl}^{-}\right)$, bikarbonat $\left(\mathrm{HCO}_{3}{ }^{-}\right)$, dan sulfat $\left(\mathrm{SO}_{4}{ }^{-}\right)$. Namun demikian, seringkali dalam analisis ion mayor beberapa ion minor dengan kandungan cukup tinggi juga digunakan. Beberapa ion tersebut adalah potasium/kalium $\left(\mathrm{K}^{+}\right)$, besi $\left(\mathrm{Fe}^{2+}\right)$, stronsium $\left(\mathrm{Sr}^{2+}\right)$, dan flourida $\left(\mathrm{F}^{-}\right)$.

Kondisi hidrologi pulau kecil dan sangat kecil memiliki dinamika kualitas air yang cepat, khususnya pada pulau koral (Delinom, 2007). Hal ini disebabkan material yang membentuk pulau koral berupa material bioklastik dengan permeabilitas yang tinggi, sehingga selain sangat mudah mengalami intrusi air laut (Gilli et al, 2012), kondisi ini menyebabkan airtanah pada pulau koral mudah mengalami pencemaran dari aktifitas manusia yang tinggal di atasnya (Falkland, 1991, 1993). Falkland (1991) menambahkan bahwa pencemaran pada 
akuifer di pulau koral akan semakin parah terjadi apabila pada pulau tersebut tidak terdapat instalasi pengolahan air limbah.

\section{Tujuan Penelitian}

Penelitian ini bertujuan untuk mengetahui evolusi hidrogeokimia airtanah yang terjadi di Pulau Koral Pramuka. Penelitian ini dimaksudkan untuk mengetahui apakah airtanah telah mengalami evolusi hidrogeokimia yang disebabkan oleh adanya proses intrusi air laut (Cahyadi dkk, 2014). Penelitian ini diharapkan menjadi awal kajian intrusi air laut di Pulau Koral Indonesia, mengingat sekitar 99,77\% jumlah pulau di Indonesia merupakan pulau kecil dan pulau sangat kecil yang banyak di antaranya merupakan pulau koral.

\section{METODE}

\section{Alat dan Bahan}

Alat dan bahan yang digunakan dalam analisis hidrogeokian meliputi:

a. Botol Sampel yang pengambilan sampel air untuk analisis laboratorium;

b. Separangkat komputer dengan aplikasi Microsoft Office untuk rekap dan analisis data; dan

c. Software Rockwork 14, untuk analisis hidrogeokimia (pembuatan diagram trilinear).

\section{Pengambilan Sampel Airtanah}

Penelitian ini dilakukan dengan pengambilan sampel secara sistematis. Pengambilan sampel dilakukan berdasarkan sistem grid yang dibuat dengan ukuran 100 meter $\times 150$ meter. Pengambilan sampel dilakukan dengan mengambil satu sampel airtanah pada setiap grid. Sampel airtanah diambil dari sumur gali dan beberapa sampel diambil dengan pengeboran dengan bor tanah. Lokasi pengambilan sampel airtanah ditunjukkan oleh Gambar 1.

\section{Data yang Digunakan}

Data yang digunakan dalam penelitian ini meliputi data kandungan ion mayor. Jumlah sampel airtanah adalah sejumlah 23 sampel yang mewakili setiap grid yang telah diguat. Ion mayor yang dianalisis terdiri dari Natrium $\left(\mathrm{Na}^{+}\right)$, Kalsium $\left(\mathrm{Ca}^{+}\right)$, Magnesium $\left(\mathrm{Ma}^{+}\right)$, Klorida $\left(\mathrm{Cl}^{-}\right.$ ), Bikarbonat $\left(\mathrm{HCO}_{3}{ }^{-}\right)$, dan Sulfat $\left(\mathrm{SO}_{4}{ }^{-}\right)$. Analisis dalam penelitian ini ditambahkan parameter ikutan yang dianalisis meliputi Kalium $\left(\mathrm{K}^{+}\right)$.

\section{Analisis Keseimbangan Ion}

Hal yang pertama kali dilakukan sebelum melakukan analisis hidrogeokimia adalah melakukan analisis keseimbangan ion (Gilli et al, 2012). Kandungan ion dalam airtanah seharusnya memiliki ion positif dan negatif yang jumlahnya sama (Effendi, 2003). Hal ini kemudian digunakan dasar untuk melakukan evaluasi terhadap hasil analisis laboratorium dengan menggunakan keseimbangan ion (Charge Balance Error/CBE) yang didasarkan pada nilai kandungan ion mayor dalam airtanah. Nilai CBE yang disarankan adalah kurang $5 \%$ untuk peralatan modern dan kurang dari 10\% untuk analisis laboratorium yang dilakukan secara manual (Hiscock, 2005). Persamaan untuk perhitungan CBE ditunjukkan oleh persamaan 3 .

$$
\text { CBE }(\%)=((\Sigma \text { Kation }-\Sigma \text { Anion }) /(\Sigma \text { Kation }+\Sigma \text { Anion })) \times 100
$$

Perhitungan CBE harus dilakukan dengan mengubah satuan ion-ion yang awalnya miligram per liter (mg/l) menjadi miliekuivalen per liter (meq/l). Konversi satuan dari mg/l menjadi meq/l dilakukan dengan persamaan 2 . dan persamaan 3.

$$
\mathrm{meq} / \mathrm{l}=\text { miligram ion } / \text { berat ekuivalen }
$$


di mana,

berat ekuivalen $\mathbf{=}$ berat molekul $/$ valensi ion

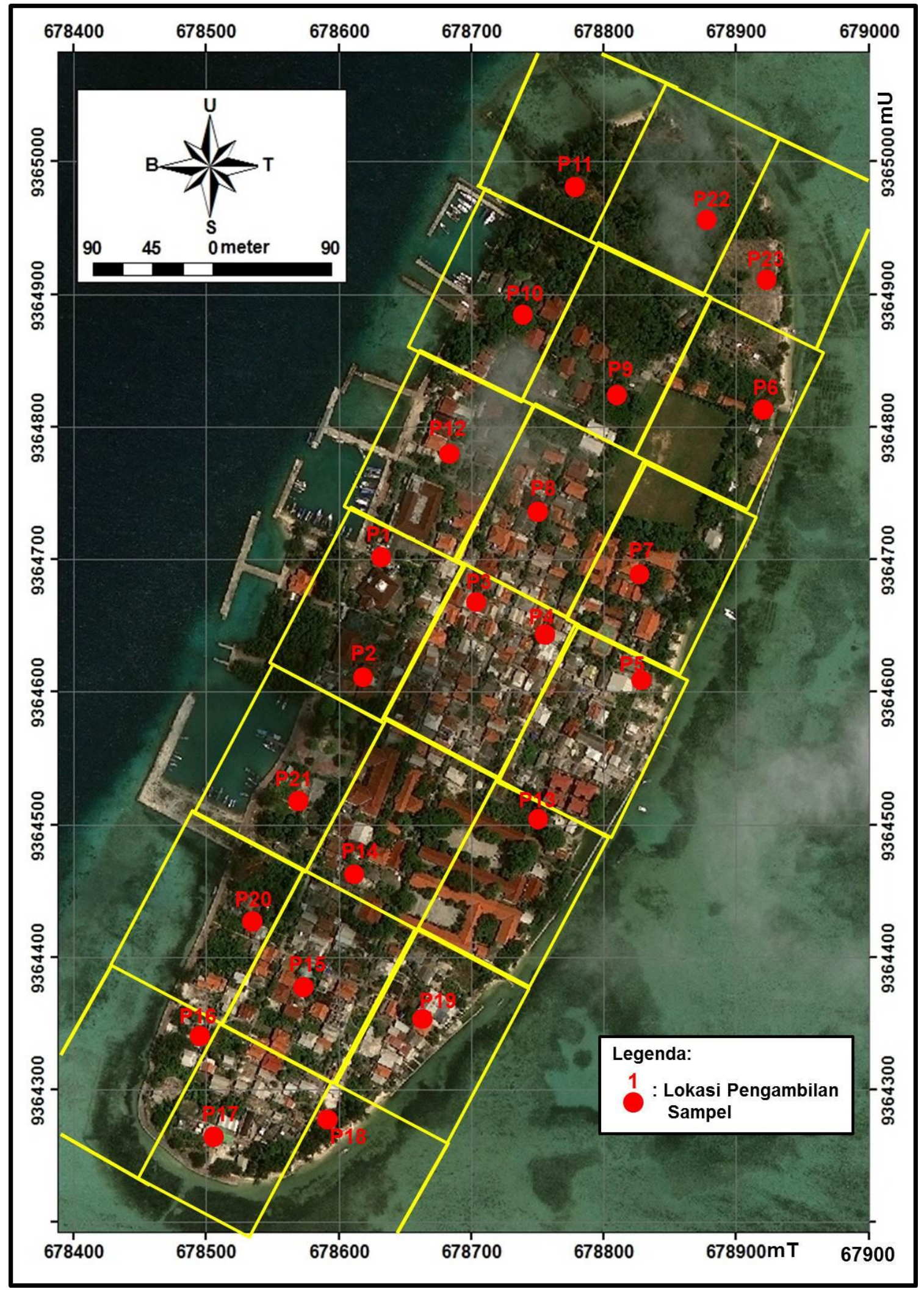

Gambar 1. Peta Lokasi Pengambilan Sampel Airtanah di Pulau Koral Pramuka 


\section{Analisis Evolusi Hidrogeokimia}

Analisis evolusi hidrogeokimia airtanah dilakukan dengan diagram piper atau diagram trilinear. Diagram trilinear lebih dikenal dengan Diagram Piper karena diagram ini dikenalkan oleh Piper yang dimuat dalam jurnal dengan judul " $A$ Graphic Procedure in The Geochemical Interpretation of Water Analysis" yang diterbitkan oleh American Geophysical Union (Hiscock, 2005). Hasil analisis akan menunjukkan suatu posisi tertentu dari kandungan airtanah yang menunjukkan evolusi kimia utama yang terjadi pada airtanah (Younger, 2007; Poehls dan Smith, 2009) .

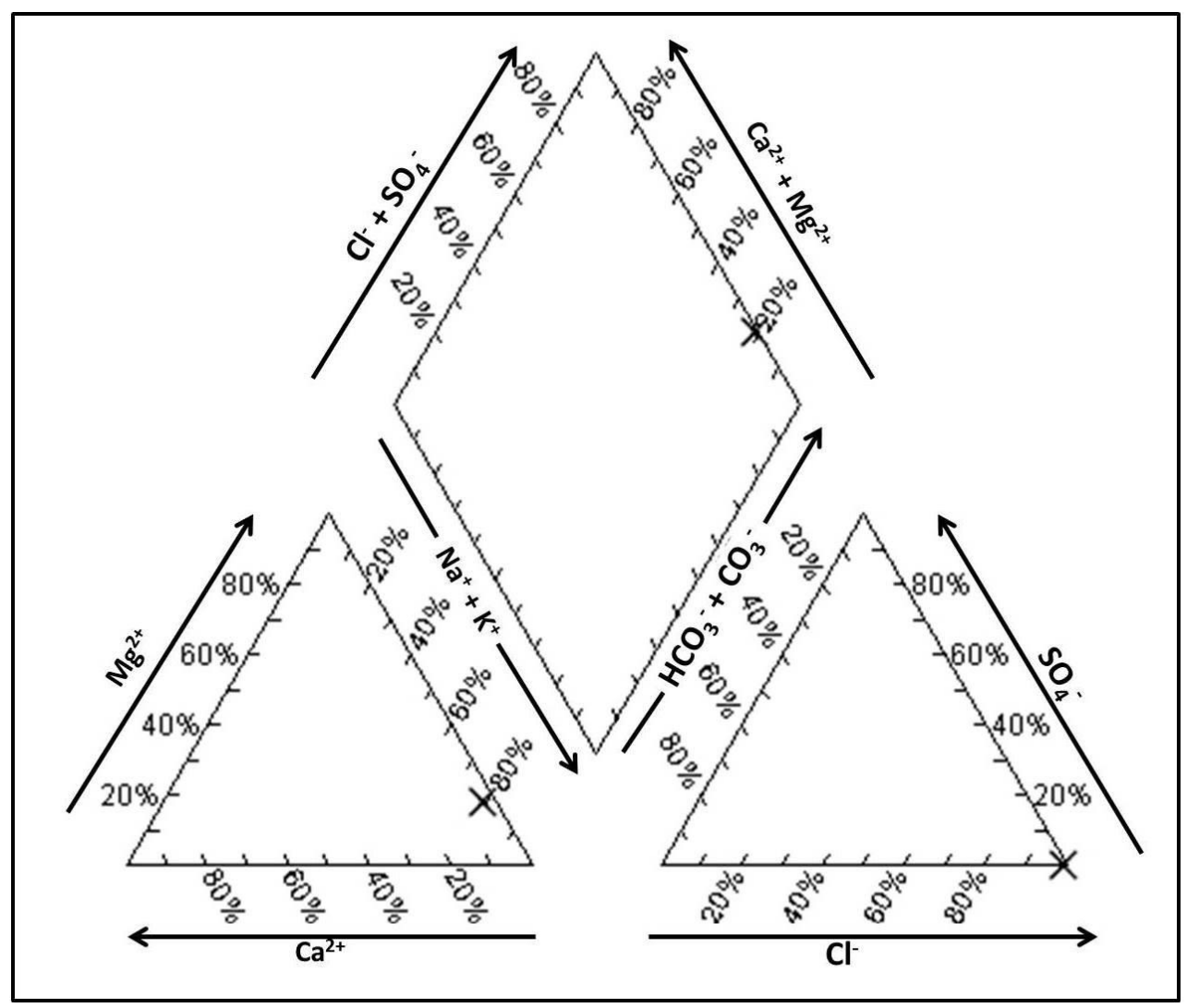

Gambar 7. Diagram Piper (Younger, 2007)

\section{PEMBAHASAN}

Analisis hidrogeokimi harus didahului dengan analisis kesetimbangan ion (Hiscock, 2005; Younger, 2007; Aris et al, 2013; Gilli et al, 2012). Hal ini dilakukan untuk memastikan bahwa hasil analisis laboratorium memiliki kualitas dan ketelitian yang baik. Komposisi ion positif (kation) dan ion negatif (anion) dalam air dalam satuan equivalent secara alami akan memiliki jumlah yang sama (Effendi, 2003). Kondisi ini menjadi dasar untuk menghitung keseimbangan ion-ion yang dihasilkan dari analisis laboratorium. Hasil analisis laboratorium yang baik pada analisis otomatis dengan peralatan modern apabila memiliki nilai CBE kurang dari $5 \%$, sedangkan untuk analisis laboratorium secara manual nilai CBE yang diperkenankan adalah kurang dari 10\% (Hiscock, 2005).

Analisis laboratorium airtanah yang dilakukan dalam penelitian ini dilakukan secara manual. Hal ini berarti bahwa nilai CBE yang masih ditoleransi adalah kurang dari $10 \%$. Tabel 1. menunjukkan hasil perhitungan CBE yang menunjukkan sejumlah 23 sampel airtanah yang digunakan dalam peneliltian ini memiliki nilai CBE kurang dari $10 \%$. 
Tabel 1. Hasil Perhitungan CBE Sampel Airtanah di Pulau Koral Pramuka

\begin{tabular}{|c|c|c|c|c|c|c|c|c|}
\hline $\begin{array}{c}\text { No } \\
\text { sampel }\end{array}$ & $\mathrm{K}^{+}$ & $\mathrm{Na}^{+}$ & $\mathrm{Ca}^{2+}$ & $\mathbf{M g}^{2+}$ & $\mathrm{Cl}^{-}$ & $\mathrm{HCO}_{3}^{-}$ & $\mathrm{SO}_{4}^{-}$ & $\begin{array}{l}\text { CBE } \\
(\%)\end{array}$ \\
\hline $\mathrm{P} 1$ & 1,87 & 2,94 & 9,00 & 24,01 & 39,48 & 4,85 & 0,60 & $-8,59$ \\
\hline $\mathrm{P} 2$ & 1,97 & 2,64 & 8,00 & 23,19 & 36,94 & 5,18 & 0,56 & $-8,77$ \\
\hline P3 & 2,29 & 3,20 & 8,50 & 18,59 & 22,28 & 5,70 & 0,44 & 6,82 \\
\hline P4 & 1,66 & 2,63 & 8,00 & 17,02 & 25,38 & 3,15 & 0,52 & 0,46 \\
\hline P5 & 1,79 & 2,89 & 12,00 & 24,51 & 42,02 & 5,05 & 0,72 & $-7,41$ \\
\hline P6 & 1,29 & 1,31 & 8,75 & 18,42 & 30,46 & 4,26 & 0,13 & $-7,86$ \\
\hline P7 & 2,06 & 2,86 & 8,50 & 12,58 & 22,56 & 5,77 & 0,15 & $-4,55$ \\
\hline P8 & 2,04 & 3,08 & 8,00 & 8,80 & 18,33 & 4,72 & 0,19 & $-2,93$ \\
\hline P9 & 1,34 & 1,32 & 10,50 & 17,76 & 21,15 & 4,85 & 0,25 & 8,16 \\
\hline $\mathrm{P} 10$ & 1,55 & 3,21 & 2,75 & 24,43 & 20,87 & 5,64 & 0,58 & 8,22 \\
\hline $\mathrm{P} 11$ & 1,89 & 2,31 & 8,00 & 23,19 & 31,30 & 3,54 & 0,19 & 0,50 \\
\hline P12 & 1,41 & 1,12 & 9,00 & 29,20 & 34,40 & 3,74 & 0,35 & 2,82 \\
\hline P13 & 1,81 & 1,49 & 6,50 & 8,64 & 17,48 & 3,93 & 0,22 & $-7,98$ \\
\hline P14 & 1,98 & 2,65 & 4,50 & 11,43 & 18,05 & 3,61 & 0,34 & $-3,35$ \\
\hline P15 & 1,65 & 2,27 & 6,00 & 22,37 & 24,25 & 4,00 & 0,33 & 6,07 \\
\hline P16 & 1,51 & 2,42 & 6,50 & 11,02 & 14,66 & 4,20 & 0,17 & 5,98 \\
\hline P17 & 1,95 & 2,33 & 7,00 & 11,60 & 21,43 & 4,39 & 0,11 & $-6,25$ \\
\hline P18 & 1,57 & 2,48 & 10,00 & 10,77 & 22,00 & 4,20 & 0,19 & $-3,05$ \\
\hline P19 & 1,99 & 2,22 & 5,50 & 12,17 & 18,89 & 4,13 & 0,15 & $-2,87$ \\
\hline P20 & 1,89 & 2,69 & 8,50 & 15,38 & 27,64 & 4,59 & 0,33 & $-6,72$ \\
\hline P21 & 1,04 & 0,93 & 9,50 & 25,00 & 34,40 & 4,59 & 0,34 & $-3,77$ \\
\hline P22 & 1,56 & 2,22 & 8,00 & 15,63 & 22,00 & 3,93 & 0,20 & 2,37 \\
\hline P23 & 1,75 & 2,66 & 9,50 & 14,64 & 22,84 & 4,06 & 0,26 & 2,48 \\
\hline
\end{tabular}

Hasil analisis diagram trilinear atau diagram piper (Gambar 2.) menunjukkan bahwa evolusi hidrogeokimia airtanah di Pulau Koral Pramuka terjadi dari tipe air $\mathrm{CaCO}_{3}$ menjadi $\mathrm{Ca}(\mathrm{Mg}) \mathrm{Cl}\left(\mathrm{SO}_{4}\right)$ atau tipe $\mathrm{N}$ dalam klasifikasi tipe air yang dibuat oleh Back dan Hanshaw (1965) dalam Talabi (2013). Meskipun demikian, jumlah ion kalsium dan sulfat yang sedikit dibandingkan dengan magnesium dan klorida kemungkinan menyebabkan tipe air dominannya akan didominasi oleh $\mathrm{MgCl}_{2}$. Kandungan $\mathrm{CaCO}_{3}$ pada airtanah berasal dari batuan gamping yang menyusun rombakan bioklastis di Pulau Koral Pramuka, sedangkan $\mathrm{MgCl}_{2}$ merupakan bukti bahwa pengaruh air laut telah masuk ke dalam sistem airtanah melaui proses intrusi air laut (Aris et al, 2013).

Segitiga kation pada diagram trilinear (kiri bawah) menunjukkan bahwa kandungan ion dalam airtanah mengelompok pada bagian kiri atas dari segitiga kation. Hal ini berarti tipe air untuk kation adalah tipe magnesium atau tipe C. Kondisi ini juga berarti bahwa kalsium pada sampel airtanah yang diambil mengalami pengurangan jumlah dan terjadi penambahan magnesium. 


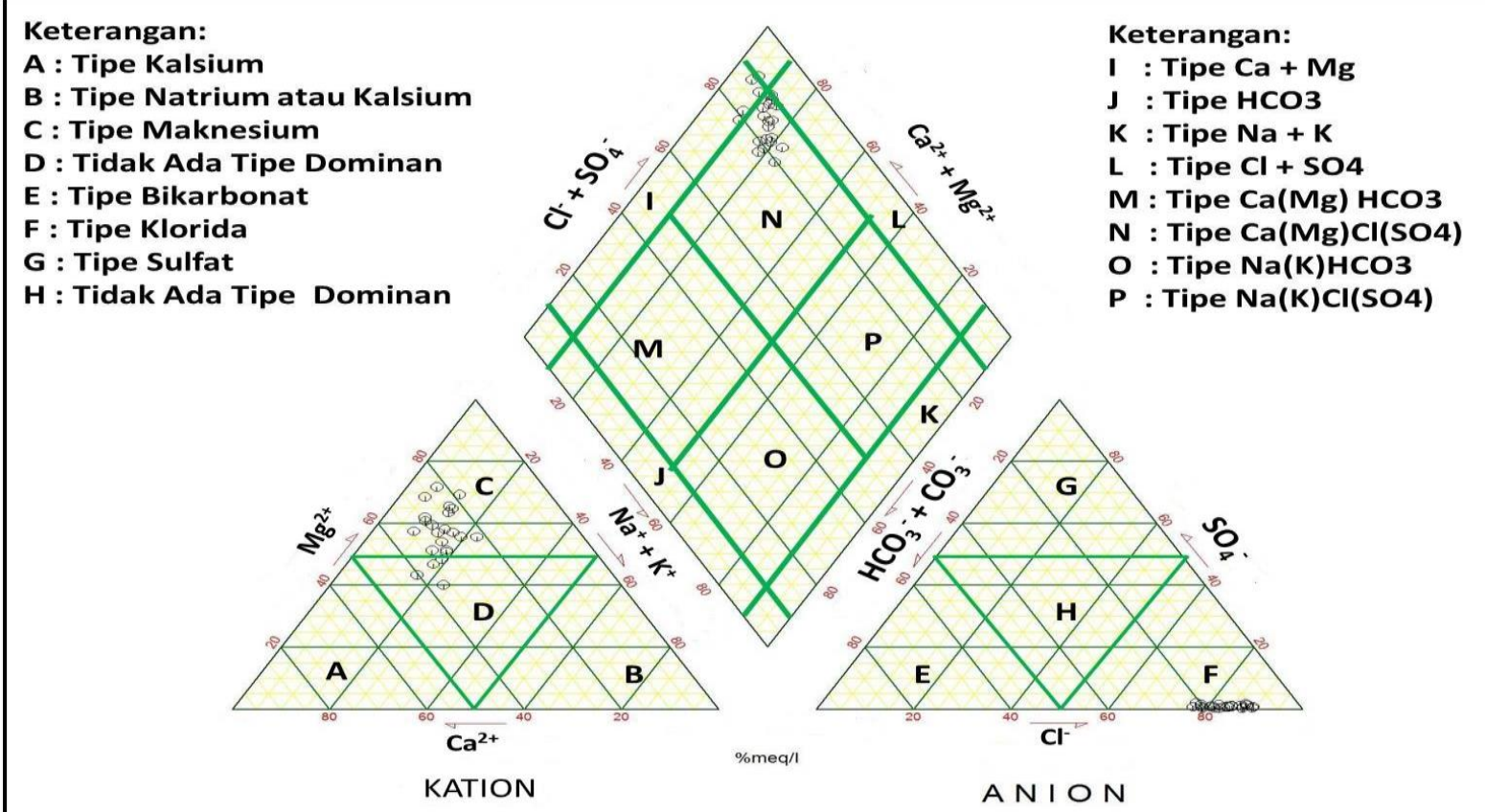

Gambar 2. Hasil Ploting Data untuk Penentuan Evolusi Hidrogeokimia dengan Diagram Trilinier Sampel Airtanah di Pulau Koral Pramuka

Segitiga anion pada diagram trilinear (kanan bawah) menunjukkan pengelompokkan kandungan anion dari sampel airtanah di Pulau Koral Pramuka mengelompok pada bagian bawah kanan. Hal ini berarti tipe anion airtanah di lokasi kajian adalah klorida atau tipe $\mathrm{F}$. Kondisi tersebut menunjukkan terjadinya penambahan jumlah klorida dan pengurangan jumlah bikarbonat.

\section{KESIMPULAN}

Berdasarkan hasil analisis yang telah dilakukan, disimpulkan bahwa tipe fasies hidrogeokimia airtanah di Pulau Koral Pramuka telah mengalami evolusi hidrgeokimia dari tipe fasies hidrogeokimia $\mathrm{CaCO}_{3}$ menjadi $\mathrm{MgCl}_{2}$. Tipe fasies hidrogeokimia $\mathrm{CaCO}_{3}$ merupakan tipe fasies hidrogeokimia yang dipengaruhi oleh batuan penyusun Pulau Koral Pramuka yang berupa rombakan bioklastik yang memiliki kandungan gamping yang tinggi. Perubahan tipe fasies hidrogeokimia yang telah terjadi dari tipe fasies hidrogeokimia $\mathrm{CaCO}_{3}$ menjadi $\mathrm{MgCl}_{2}$ menunjukkan adanya dampak dari intrusi air laut.

\section{PENGHARGAAN}

Penelitian ini merupakan sebagian dari tesis penulis pertama, serta merupakan bagian kecil dari tesis penulis pertama dan penelitian yang dibiayai oleh Hibah Penelitian Dosen Fakultas Geografi Univeristas Gadjah Mada Tahun 2015 yang dibiayai melalui Dana Penerimaan Negara Bukan Pajak Fakultas Geografi UGM Tahun 2015 yang berjudul "Analisis Dampak Intrusi Air Laut terhadap Airtanah Berdasarkan Karakteristik Hidrogeokimia di Pulau Koral Pramuka, Kepulauan Seribu, DKI Jakarta."

\section{REFERENSI}

Aris, A.Z.; Praveena, S.M. dan Isa, N.M. 2013. Groundwater Composition and Geochemical Controls in Small Tropical Island of Malaysia: A Comparative Study. dalam Wetzelhuetter, C. 2013. Groundwater in The Coastal Zones of Asia-Pacific. Dordrecht: Springer. 
Cahyadi, A. 2012. Permasalahan Sumberdaya Air Pulau Kecil. Prosiding Seminar Lingkungan Hidup 2012. Magister Ilmu Lingkungan, Universitas Diponegoro Semarang.

Cahyadi, A. 2013. Menyelamatkan Masa Depan Pulau Kecil di Indonesia: Sebuah Pembelajaran dari Pulau Pramuka, Kepulauan Seribu. Makalah dalam lomba karya tulis "Potert Indonesia 2014". Moskow: Pimpinan Cabang Istimewa Muhammadiyah Rusia.

Cahyadi, A., Hidayat, W. Dan Fatchurohman, H. 2014. Kajian Dampak Intrusi Air Laut pada Akuifer Pulau Koral Sangat Kecil Berdasarkan Analisis Perbandingan Ion Mayor (Studi Kasus di Pulau Koral Panggang, Kepulauan Seribu, DKI Jakarta). Makalah dalam Pekan IImiah Tahunan (PIT) Ikatan Geograf Indonesia (IGI), Tanggal 15 November 2014 di Universitas Negeri Yogyakarta.

Delinom, R.M. 2007. Sumber Daya Air di Wilayah Pesisir dan Pulau-Pulau Kecil di Indonesia. Bandung: LIPI Press.

Effendi, H. 2003. Telaah Kualitas Air: Bagi Pengelolaan Sumberdaya dan Lingkungan Perairan. Yogyakarta: Kanisius.

Falkland, C.A.1991. Hydrology and Water Resources of Small Island: A Practical Guide. Paris: UNESCO.

Falkland, C.A. 1993. Hydrology and Water Management in Small Tropical Island. Proceeding of The Yokohama Symposium on Hydrology on Warm Humid Regions. July, 1993.

Fetter, C.W., 1988. Applied Hydrogeology. New York: Mac Millan Publishing.

Gilli, E.; Mangan, C. dan Mudry, J. 2012. Hydrogeology: Objectives, Methods, Applications, diterjemahkan dari Bahasa Perancis oleh Chloe Fandel. Boca Raton: CRC Press.

Hehanusa, P.E. 1993. Morphogenetic Classification of Small Island as Basis for Water Resources Planning in Indonesia. Proceeding Workshop on Small Island Hydrology. Batam Indonesia.

Hem, J.D. 1970. Study and Interpretation of the Chemical Characteristic of Natural Water. Washington D.C.: United State Government Printing Office.

Hiscock, K.M. 2005. Hydrogeology: Principles and Practice. Oxford: Blackwell Publishing. Ongkosongo, O.S.R. 2011. Lingkungan Fisik Pulau Pramuka. dalam Ongkosongo, O.S.R.; Wijonarko, S. dan Afadlal. 2011. Rona Lingkungan Pulau Pramuka. Jakarta: Lembaga IImu Pengetahuan Indonesia (LIPI), Pusat Penelitian Oseanografi, Balai Dinamika Laut, Kolompok Penelitian Geologi Laut.

Poehls, D.J. dan Smith, G.J. 2009. Encyclopedic Dictionary of Hydrogeology. Burlington, USA: Elsevier.

Santosa. L.W. 2010. Kajian Genesis Bentuklahan dan Pengaruhnya Terhadap Hidrostratigrafi Akuifer dan Hidrogeokimia Sebagai Geoindikator Evolusi Airtanah Bebas pada Bentanglahan Kuarter Kabupaten Kulonprogo Bagian Selatan, Daerah Istimewa Yogyakarta. Disertasi. Yogyakarta: Fakultas Geografi Universitas Gadjah Mada.

Stuyfzand, P.J. 1986. A New Hydro-chemical Classification of Water Types: Principles and Application to the Coastal Dunes Aquifer System of the Netherlands. Prosiding dalam Seminar Salt Water Intrusion Meeting. The Delft.

Talabi, A.O. 2013. Hydrogeochemistry and Stable Isotopes $\left(\delta^{18} \mathrm{O}\right.$ and $\left.\delta^{2} \mathrm{H}\right)$ Assessment of Ikogosi Spring Waters. American Journal of Water Resources. 2013, 1(3). Hal: 2533.

Todd, D.K. 1980. Groundwater Hydrology. New York: John Wiley and Sons.

Younger, P.L. 2007. Groundwater in The Environment. Oxford, United Kindom: Blackwell Publishing. 